THE CHEMICAL AND PATHOLOGICAL CAUSES OF ALBUMINURIA.

To the Editor of The Lanceí.

SIR,-I think it prudent to reply to the letter of "M.D." in your last Number, rather with the view of placing chemical pathology in its right position, than to defend my own opinions on albuminuria, to which, in fact, no valid objections have been raised.

I may, however, observe, that I have given great attention to the local pathology of the skin, and I have dwelt upon the pathology of the internal organs so far as is consistent with the scope of my paper. "M.D." seems to think that there can be no pathology except such as is discovered by a post-mortem examination. I did not pretend to exhaust the subject.

If $I$ have not noticed the doctrine of congestion, it is not because I was not aware of it, for I have been reminded of it in former reviews; but simply because I do not attribute to it that importance, either as a new discovery, or as an essential lesion in albuminuria, which other writers consider it to deserve. I admire the beautiful experiments that proved albuminuria to be a result of compression of the vessels of the kidneys; but, believe that, practically, it was well understood before that congestion was a preliminary step to general albuminous effusions. In dropsy, too, the mere fact of congestion of the kidneys is of minor importance. I cannot dilate.

It is the great fault of structural pathology that it tends to limit the considerations of the inquirer to certain facts immediately under the eye, and does not embrace general principles. It affords us also but slight indications of the method of cure. Now, chemical pathology cannot be satisfactorily followed out unless the function of every organ be taken into account at the time of estimating the value of its evidence; it directly leads us to a knowledge of what may be called the balance of organs, it requires and gives us a more enlarged view of the operations of the economy under disease, and it traces every link in the chain of causes which constitute the disease. It prevents partial views, and, consequently, erroneous conclusions.

Instead of being deterred by the risk of error, we should push forward to endeavour to remove it.

A diseased structure does not necessarily indicate a mode of cure; the deficiency, or excess, of any principle, either in the fluids or solids, as chemically discovered, denotes at once the treatment to be adopted. For these, and many other reasons, I would press onwards the march of organic chemistry, and induce all observing men to make it the object of their especial consideration. I remain, Sir, yours very truly,

Camberwell, August 19, 1844.

George Ross.

CAMPHOR A PRESERVATIVE OF ERGOT OF RYE.

To the Editor of THE LANCET.

SrR,-I was not a little surprised to read some remarks by Mr. Rawle, stating that he had discovered camphor to be a preservative of ergot of rye. I can only say that I have been in the habit of using it for the last nine or ten years, but not exactly in the manner described by him. I order the camphor to be mixed with the powdered ergot, in the proportion of a grain in every scruple. By this means I think the camphor is more intimately diffused throughout the whole than can possibly take place by the plan proposed by Mr. Rawle. I do not give this either as a new, or, indeed, my own discovery; for I adopted the method by having seen it in the practice of Mr. Spurgin, an old practitioner also at Saffron Walden, and from whom I have every reason to believe that your correspondent also obtained the same information, he having been engaged in the same gentleman's practice.

If you think the above worthy of notice, you will oblige, Sir, yours respectfully

Staines, August 28, 1844.

\section{A NEW MODE OF PRESERVING THE ERGOT} OF RYE.

By R. M. NunN, Esq., Wexford.

Having seen in a late number of The LaNCET (August 10th, page 611), some observations on the preservation of the secale cornutum, by Mr. Rawle, of Saffron Walden, and, as it is a subject to which $I$ have given some attention, I can recommend the following plan for the preservation of this valuable but perishable drug as one on which the practitioner can confidently rely. Procure a choice specimen of the ergot, reduce it to powder, have in readiness a sufficient number of two-drachm bottles, into each bottle put one drachm of sulphuric ether (spirits of wine may do as well), and then press in two drachms of the powdered drug (if the bottles are of the proper size it will require a slight pressure to make them hold this quantity); now cork it well, and either seal with wax, or cover with bladder. When required for use, put the contents of one of these bottles into a tumbler, and pour on it a small quantity of boiling water; a violent effervescence takes place, which quickly subsides, and during which the ether is evaporated; you may then add as much more boiling water as may be necessary. It is instantly fit for use.

\section{FOREIGN DEPARTMENT.}

THE RESEARCHES OF M. JOBERT (DE LAMBALLE) ON THE STRUCTURE OF THE UTERUS.

M. Jonert, surgeon to the Hospital St. Louis, is an enlightened and conscientious observer, whose labours seldom fail to throw light on the subject which he studies. We extract the subjoined account (condensed) of his researches on the anatomy of the uterus from $\mathbf{M}$. Malgaigne's "Journal de Chirurgie," one of the best conducted French periodicals of the day.

The uterus is generally considered to be formed of proper tissue, of two membranes, of numerous vessels, and of cellular tissue uniting these elements.

The existence of subperitoneal cellular tissue uniting the abdominal serous membrane to the uterine tissue, is generally admitted. This cellular tissue, which is said to entirely surround the uterus, is considered by some authors to present the physical characters of yellow fibrous tissue, and by others to be susceptible of muscular transformation during pregnancy. My researches, says M. Jobert, have shown me that there is no cellular tissue or yellow fibrous tissue underneath the peritoneal covering of the uterus. Cellular tissue, on the contrary, is evident, at all periods of life, round the Fallopian tubes, the round ligaments, the ovaries, and a part of the uterine neck. The peritoneal serous surface is elsewhere joined to the entire extent of the uterine substance by muscular fibres, so adherent that it is difficult, except near the neck, to separate it from them without bringing some of them away. When this separation is effected on the posterior surface of the uterus, the torn fibres present a longitudinal disposition. On the anterior surface, on the contrary, the fibres appear transversal and oblique. At the fundus of the organ their direction varies, and cannot be always ascertained. This union of the peritoneum and of the body of the uterus is also evident in the female of the monkey, in the sow, the ewe, and the mare; in these animals the cellular tissue is abundant round the vagina, and in the large ligaments. The adhesion between the peritoneum and the cornua of the uterus is also effected by muscular fibres.

I think, therefore, that we may establish as a law that the peritoneum is connected with the proper tissue of the uterus, in woman and in animals, by muscular fibres, never by cellular tissue or by yellow fibrous tissue, and that cellular tissue, in the entire animal series, is the means of union between the peritoneum and the neck of the uterus, the vagina, and the large ligaments. I have never found any trace of cellular tissue in the proper substance of the uterus.

Is there a mucous membrane on the internal surface of the uterine cavity? Most of those who have admitted 